\title{
Argumentação de estudantes na criação e crítica de analogias sobre o Modelo Atômico de Thomson
}

\author{
Students' argumentation in the creation and critique of \\ analogies of Thomson's Atomic Model
}

\author{
Tatiana Costa Ramos ${ }^{1}$ \\ https://orcid.org/0000-0001-6572-3822 \\ Paula Cristina Cardoso Mendonça ${ }^{2}$ \\ https://orcid.org/0000-0003-1762-4840 \\ Nilmara Braga Mozzer ${ }^{2}$ \\ https://orcid.org/0000-0002-2060-7964
}

\begin{abstract}
Resumo: Neste trabalho buscamos compreender como a estratégia de criação e crítica de analogias por estudantes de Química pode favorecer o engajamento em argumentação e a aprendizagem do modelo atômico de Thomson. Foi produzida uma Unidade Didática e o desenvolvimento da mesma em uma turma de $1^{\circ}$ ano do ensino médio foi registrado em áudio e vídeo. Um estudo de caso foi desenvolvido para um grupo de estudantes. A análise do caso indica que os estudantes se envolveram em argumentação ao apresentarem as correspondências e limitações das comparações, o que favoreceu a defesa de posicionamentos, a refutação e a avaliação das ideias sobre as comparações deles. A estratégia contribuiu para a aprendizagem de aspectos complexos relacionados ao modelo, como a movimentação dos elétrons. Consideramos que essa estratégia possa ser potencialmente útil no contexto do ensino de Química.
\end{abstract}

Palavras-chave: Argumentação. Analogia. Relações analógicas. Modelo atômico de Thomson. Ensino de química. Ensino médio.

\begin{abstract}
In this paper, we aim to explain how the strategy for the creation and critique of analogies of Chemistry students can favor engagement with argumentation and the learning of the atomic model proposed by Thomson. A Didactic Unit was produced and used with a first-year high school class. The class was recorded on audio and video, and a case study was developed of a group of students. The analysis of the case indicates that the students were involved in argumentation when they presented the correspondences and limitations of comparisons, which favored the defense of their opinions, the rejection, and assessment of ideas concerning their comparisons. The strategy contributed to the learning of complex aspects related to the model, such as the movement of electrons. We believe that this strategy may be potentially useful in the context of Chemistry teaching.
\end{abstract}

Keywords: Argumentation. Analogy. Logical relations. Thomson's Atomic Model. Chemistry teaching. Secondary school.

\footnotetext{
${ }^{1}$ Universidade Federal de Ouro Preto (UFOP), Programa de Pós-graduação em Educação, Ouro Preto, MG, Brasil.

${ }^{2}$ UFOP, Instituto de Ciências Exatas e Biológicas, Ouro Preto, MG, Brasil. E-mail: paulamendonca@iceb.ufop.br
} 


\section{Introdução}

Sob uma perspectiva epistemológica sociocultural, a ciência, a educação em ciências e a pesquisa em educação científica são vistas como atividades sociais conduzidas dentro de estruturas institucionais e ambientes culturais (BAKER, 2009; LONGINO, 2002). A partir dessa perspectiva, as interações sociais no contexto de ensino e aprendizagem ganham destaque e, consequentemente, a participação dos estudantes no discurso da sala de aula. Apesar disso, sabemos que prevalece nas salas de aula de ciências a retórica das conclusões científicas e a ênfase no discurso do professor, autoridade epistêmica detentora das verdades científicas (SASSERON; DUSCHL, 2016).

Com o objetivo de contribuir para a inserção dos estudantes no discurso de sala de aula, julgamos fundamental a criação de estratégias para desenvolver ambientes argumentativos. A argumentação é centrada em interações dialógicas, por isso, no contexto de ensino, ela oportuniza a expressão de ideias pelos estudantes, sendo potencialmente útil para criação de ambientes de negociação de significados na medida em que os estudantes têm oportunidades de propor, avaliar e comunicar suas ideias.

Neste artigo defendemos a estratégia de criação e crítica de analogias pelos estudantes com a intenção de fomentar a aprendizagem de ciências a partir da argumentação e de apoiar a inserção dos estudantes na elaboração de representações de conceitos e negociação de significados. Aliado a isso, consideramos a importância dos estudantes serem envolvidos em práticas autênticas da ciência, tanto como meio deles construírem conhecimento e compreensões aprofundadas sobre os conteúdos, quanto para compreenderem as próprias práticas da comunidade científica (JIMÉNEZ-ALEIXANDRE; CRUJEIRAS, 2017).

As analogias e a argumentação são comumente utilizadas para ajudar na compreensão e na comunicação de ideias no âmbito da ciência (KELLY; REGEV; PROTHERO, 2008; NERSESSIAN, 1992). No entanto, conjugar essas práticas no Ensino de Ciências não é algo comum. Assim, em função dessa conjugação, pretendemos contribuir para o campo de pesquisas ao analisar o potencial das analogias como promotoras de processos argumentativos no ensino.

No contexto do Ensino de Física, os autores Emig et al. (2014) desenvolveram uma pesquisa na qual os estudantes vivenciavam situações de comparação de cenários análogos (situações, objetos, fenômenos etc., que apresentam relações de similaridade com o conceito alvo). Na pesquisa desses autores os estudantes eram estimulados a eleger, entre dois desses cenários, aquele que melhor explicasse determinado conceito. Os autores observaram que os estudantes utilizavam os dados para justificar seus pontos de vista e refutar as ideias dos colegas sobre qual seria o melhor análogo.

No presente trabalho propomos analisar o potencial das analogias como fomentadoras de ambientes argumentativos numa situação diferente daquela projetada pelos pesquisadores Emig et al. (2014). Em lugar da discussão de cenários análogos, analisamos a argumentação por meio da criação e crítica de analogias pelos próprios estudantes. Isso porque, no processo de criação e crítica de analogias os estudantes são motivados a se comunicar, expressar suas ideias e negociar suas representações sobre os conceitos.

Além disso, nosso trabalho visa contribuir para o ensino de Química na medida em que apresenta uma estratégia para se discutir o tema modelo atômico de Thomson. Esse tema é 
considerado abstrato e de difícil compreensão pelos estudantes. Por isso, no seu ensino é comum o uso de analogias prontas, em especial, a do pudim de ameixa ${ }^{3}$ e o átomo de Thomson. Essa comparação visa relacionar as seguintes similaridades: as passas dispersas por toda extensão do pudim e os elétrons dispersos por toda extensão do átomo; e a massa do pudim distribuída de maneira uniforme e a distribuição uniforme da parte positiva do átomo.

Atualmente, encontramos em um livro do Programa Nacional do Livro Didático (PNLD) de 2018, a seguinte afirmação: "Historicamente, o modelo atômico de Thomson ficou conhecido como um bolo inglês, chamado pudim de ameixas" (SANTOS; MÓL, 2016, p. 158, grifos dos autores). Essa analogia, ainda que muito difundida nos materiais didáticos, é problemática para o ensino do modelo atômico de Thomson.-

Pesquisas como as de Ramos e Mozzer (2018) e de Lopes e Martins (2009) evidenciam que a comparação não auxilia os estudantes a compreender a dinamicidade proposta por Thomson em seu modelo, no qual os elétrons encontram em constante movimento. Ao contrário, essa analogia pode contribuir para o desenvolvimento de ideias incoerentes sobre esse aspecto do átomo na medida em que se compara a distribuição de passas incrustadas em um pudim com a distribuição dos elétrons no átomo. Aliado a isso, o pudim de ameixas proposto para representar as ideias do átomo não é um análogo familiar aos estudantes brasileiros.

Desse modo, diante dessa problemática no ensino do modelo atômico de Thomson associado à analogia, nosso trabalho também visa contribuir com uma estratégia favorável ao ensino e compreensão do tema. Para isso, buscamos responder duas questões de pesquisa neste artigo: Como os estudantes se envolvem em argumentação quando estão em um processo de elaboração, crítica e revisão de comparações sobre o modelo atômico de Thomson? Como essa estratégia contribuiu para a aprendizagem deles sobre o modelo?

\section{Argumentação na perspectiva de Baker}

Adotamos as definições de Baker (2009) para análise da argumentação no contexto do ensino de química, pois o mesmo vislumbra a argumentação a partir de situações coletivas e de relações interpessoais.

Em sala de aula é comum os estudantes serem colocados diante de problemas para que eles possam encontrar soluções para os mesmos por meio das interações que estabelecem uns com os outros. Para Baker (2009), quando os problemas são resolvidos coletivamente pode-se gerar um novo tipo de problema, denominado interlocutionary ${ }^{4}$. Segundo o autor, os problemas desse tipo requerem uma decisão em conjunto ou uma combinação de soluções

\footnotetext{
${ }^{3}$ Embora originalmente receba esse nome, trata-se de uma sobremesa de origem inglesa, que contém passas, ao invés de ameixa, distribuídas por toda a extensão de sua massa. Esse tipo de sobremesa não é comum no Brasil. Ele se assemelha a um panetone.

${ }^{4}$ Optamos por não traduzir o termo interlocutionary para a língua portuguesa, pois não encontramos uma tradução adequada. Portanto, para sermos mais fidedignos com as ideias do autor, utilizaremos o termo interlocutionary da língua inglesa.
} 
para resolvê-los. Um exemplo desse tipo de problema seria o da tomada de decisão coletiva sobre qual política energética adotar. Quando esse problema é trabalhado em grupo, diferentes soluções podem ser propostas, tornando-se necessária uma decisão conjunta ou uma combinação de soluções para se tomar a decisão (BAKER, 2009).

As interaçôes argumentativas podem ocorrer durante a resolução dos problemas do tipo interlocutionary. Essas interações podem ser definidas como tentativas para decidir sobre soluções alternativas. Nesse sentido, os argumentos são as afirmativas que contém informações que alteram o grau de aceitabilidade das soluções dos problemas. Essas informações podem advir de uma variedade de fontes, incluindo fontes didáticas, vida cotidiana, escolaridade anterior e a partir da própria situação de resolução de problemas, caso em que os argumentos podem corresponder às "bases" em que os estudantes inicialmente propuseram as soluções (BAKER, 2009).

Desse modo, a argumentação é um recurso para o estudante se comunicar e para auxiliá -lo a reconhecer a plausibilidade de alguma solução para um problema - do tipo interlocutionary -, após ter dado a ele os fundamentos (informações) necessários para fazê-lo (BAKER, 2009).

\section{Analogias na Ciência e no Ensino de Ciências}

Uma analogia é definida por Gentner (1989) como um tipo de comparação na qual um conceito ou uma situação familiar (domínio análogo) compartilha relações de similaridade com um conceito científico a ser ensinado (domínio alvo).

No contexto científico, os cientistas utilizam analogias para auxiliá-los a: entender e explicar fenômenos abstratos, produzir novos conhecimentos, comunicar suas ideias, resolver problemas, identificar novos problemas, elaborar novas hipóteses, e desenvolver e expressar seus modelos (COLL, 2005; DUNBAR; BLANCHETTE, 2001). Modelos na ciência são entendidos como uma representação parcial de um objeto, sistema, fenômeno ou processo, que se destina a uma finalidade específica e que pode ser modificado (GILBERT; BOULTER; ELMER, 2000).

No contexto de ensino, como evidenciado no trabalho de Coll (2005), a criação de analogias pelos estudantes permite que os professores acessem mais facilmente as ideias dos mesmos e os auxilie na (re)construção de representações sobre o conhecimento científico. Além disso, segundo esse autor, os estudantes podem visualizar aspectos incoerentes de suas representações por meio do processo de crítica de analogias.

A pesquisa realizada por Justi e Mendonça (2008) também demonstra o potencial da criação de analogias pelos estudantes como um modo de expressar as ideias e representações sobre os conceitos estudados por eles. As pesquisadoras observaram que as analogias permitiram que os estudantes expressassem suas ideias sobre o tema de ligação Química de forma criativa e autêntica, favorecendo o envolvimento deles na discussão dessas ideias. Tais resultados evidenciam o potencial de ocorrência de interações dialógicas na discussão das analogias.

Esse processo deve ser pensado como uma coelaboração no qual a atuação do professor é de fundamental importância (ANDRADE; MOZZER, 2016; COLL, 2005), pois ele deverá conduzir a discussão das analogias criadas pelos estudantes no sentido de auxiliá-los no desenvolvimento de suas ideias em direção às científicas, ou seja, aquelas que fundamentam o conceito alvo. Para isso, é necessário que o mapeamento (processo em que se evidenciam as correspondências das similaridades entre os domínios comparados) e a crítica dessas 
similaridades sejam intencionalmente requisitados pelo professor, inclusive para que todos os estudantes compreendam as ideias uns dos outros (MOZZER; JUSTI, 2015).

\section{Aspectos metodológicos}

\section{Unidade Didática}

Elaboramos uma Unidade Didática (UD) para instrução dos temas modelos atômicos Dalton e Thomson, que visa proporcionar aos estudantes a oportunidade de criar e criticar analogias sobre esses temas para fomentar o engajamento deles em interações argumentativas, na medida que oportuniza a expressão e discussão de suas ideias (RAMOS; MENDONÇA; MOZZER, 2016). Em Ramos, Mendonça e Mozzer (2016) esboçamos um esquema dessa Unidade Didática e maiores detalhes sobre a proposta podem ser encontrados em Ramos (2017).

\section{Coleta de dados}

A pesquisa foi realizada nas aulas de Química de uma turma do primeiro ano do Ensino Médio de uma escola da rede pública situada em uma cidade do interior de Minas Gerais. A faixa etária dos estudantes era entre 14 e 16 anos. A seleção desse nível de ensino se deu a partir da escolha de se trabalhar com o tema de modelos atômicos que, naquele contexto, era discutido no primeiro ano do Ensino Médio.

A pesquisa ocorreu naquele cenário devido ao interesse da professora de Química, regente da turma em participar do estudo e ao nosso interesse em investigar um contexto de ensino de uma escola da rede pública.

A coleta ocorreu durante quatro semanas consecutivas, sendo realizada em 10 (dez) aulas de 50 (cinquenta) minutos cada. Todas as aulas foram registradas em áudio e vídeo. Durante as aulas, estiveram presentes a professora colaboradora, a pesquisadora (primeira autora deste trabalho) e um auxiliar de filmagem.

$\mathrm{Na}$ tentativa de facilitar a comunicação entre os estudantes e de favorecer a ocorrência de interações argumentativas, eles foram organizados em grupos em todos os momentos da coleta. É importante destacar que os estudantes daquela turma não estavam acostumados a vivenciar atividades que visavam à discussão, proposição e comunicação de ideias como as atividades que envolvem criação e crítica de analogias e argumentação sugerem.

A pesquisadora atuou como observadora participante no cenário daquela turma, auxiliando os grupos de estudantes no esclarecimento de dúvidas sobre os temas, na apresentação suas ideias e no envolvimento em interações argumentativas, durante a maior parte do tempo das atividades. Tal auxílio também foi realizado pela professora colaboradora. Para Cohen, Manion e Morrison (2011), a observação participante permite o desenvolvimento de relações informais entre o pesquisador e os indivíduos pesquisados e, por isso, contribui para retratar o contexto em configurações relativamente mais naturais.

Em observação aos princípios da ética, esta pesquisa foi aprovada por um Comitê de Ética em Pesquisa e, como os estudantes tinham idade menor que 18 anos, os responsáveis por eles assinaram um Termo de Consentimento Livre e Esclarecido. Além disso, a professora da 
turma explicou sobre a pesquisa aos estudantes e eles também leram e assinaram um termo, confirmando sua participação livre e espontânea na pesquisa. Para preservação da identidade dos estudantes, da professora e da pesquisadora, utilizamos nomes fictícios.

\section{Análise de dados, seleção e caracterização da amostra}

Em um primeiro momento, a pesquisadora assistiu a todos os vídeos das aulas que envolveram o desenvolvimento da UD e transcreveu todos os momentos em que ocorreram comunicação entre os estudantes e destes com a professora colaboradora e com a pesquisadora durante as atividades. A transcrição foi feita a partir da conjugação entre a visualização dos vídeos, escuta dos áudios, consulta das atividades escritas, dos desenhos, dos gestos utilizados pelos estudantes durante suas falas e dos modelos concretos feitos por eles.

A integração de todos os dados nos permitiu desenvolver um estudo de caso para um dos grupos de estudantes. Para Stake (2000), esse tipo de estudo é uma escolha do que deve ser estudado e, uma questão fundamental, é o conhecimento derivado do caso, ou seja, o que se aprende ao estudá-lo.

O critério de seleção do grupo investigado foi a acessibilidade dos estudantes. Selecionamos aquele grupo que deu maior abertura para a presença da pesquisadora nas discussões.

Após a seleção do grupo e a transcrição dos dados, ocorreu a análise da argumentação. Essa análise foi feita a partir da seleção dos momentos em que ocorreram interações argumentativas naquele grupo, de acordo com a perspectiva de Baker (2009), discutida na subseção a seguir.

Foi realizada a triangulação dos dados entre as autoras desse trabalho, a partir da checagem das interações argumentativas. Isso foi realizado com as intenções de: identificá-las e de avaliar sua coerência com as ideias de Baker (2009) sobre argumentação. Também realizamos a triangulação dos dados para a avaliar a consistência da nossa categorização das comparações com a tipologia de Gentner (1989).

\section{Critério para análise da argumentação}

Para avaliarmos a argumentação, inicialmente selecionamos os diálogos em que ocorria uma resolução de problemas pelos estudantes. O recorte era iniciado no momento da problematização para os estudantes e finalizava quando o problema havia sido resolvido por eles (BAKER, 2009).

Segundo Baker (2009), esse tipo de interação ocorre quando as pessoas expressam informações adicionais, fundamentam suas opiniões relativas ao problema, analisam a coerência do conjunto de informações e os raciocínios expressos por opiniões divergentes, para, posteriormente, se decidirem sobre a resolução do problema. Nessas situações, o grau de aceitabilidade da solução do problema é influenciado diretamente por informações adicionais e a solução para o problema é construída na colaboração entre as pessoas.

O autor denomina tese a suposta solução para o problema em questão, cuja aceitação é determinada com base em argumentos. Como citado no início deste trabalho, os argumentos 
são aquelas afirmativas nas quais são expressas informações que alteram a aceitabilidade da solução do problema.

Em nosso trabalho, os indivíduos que participaram da interação argumentativa foram os estudantes, a professora colaboradora e a pesquisadora. Os tipos de teses discutidas por eles foram: análogos, analogias e outros tipos de comparações. Consideramos as comparações e os análogos sugeridos pelos estudantes como teses, porque a partir deles os estudantes expressavam suas ideias sobre o tema. Desse modo, ao discutirem sobre suas comparações e análogos, os estudantes estavam discutindo sobre as ideias que fundamentavam suas representações e, neste sentido, elas constituíam as suas tentativas de representação do átomo (solução do problema).

Devido à extensão da interação argumentativa analisada no presente trabalho, fizemos um recorte da mesma visando manter (i) a lógica do problema (início, meio e fim) e (ii) os pontos cruciais do diálogo para a compreensão das negociações das representações pelos estudantes. Utilizamos o símbolo [...] para representar tais recortes.

\section{Critério para análise das comparações (tipologia)}

As comparações criadas e mapeadas pelos estudantes durante as interações argumentativas foram classificadas de acordo com a tipologia de Gentner (1989). Segundo a autora, as comparações podem ser diferenciadas de acordo com os tipos de similaridades propostas entre os domínios análogo e o alvo. Alguns dos tipos mais comuns de comparações são: mera aparência, similaridade literal e analogias.

Quando as comparações se restringem a atributos de objetos, ou seja, correspondências de similaridades físicas e superficiais entre os dois domínios comparados, elas são chamadas de comparações de mera aparência. No caso em que os dois domínios compartilham, além das similaridades físicas, relações de similaridade (estruturais, funcionais, causais, entre outros), as comparações são chamadas de similaridade literal. São chamados de analogias, os casos em que as comparações entre os dois domínios são, exclusivamente, entre relações de similaridade (GENTNER, 1989).

Utilizamos a tipologia de Gentner (1989) para classificar as comparações porque acreditamos, como a autora, que comparações puramente relacionais, como as analogias, demandam abstrações sobre o domínio alvo e, portanto, são indicativas de uma compreensão mais elaborada do mesmo do que aquelas fundamentadas apenas em similaridades físicas (comparações de mera aparência) ou mesmo em ambas as similaridades - físicas e relacionais (similaridade literal). Assim, classificamos os tipos de comparações criadas pelos estudantes com intuito de observar as relações que poderiam existir entre o processo argumentativo e a discussão gerada pelos tipos de comparações.

As comparações discutidas durante as interações foram apresentadas em quadros divididos em três colunas que indicam: o análogo, o alvo e o tipo de correspondência (mapeamento) entre eles. Nesses quadros são apresentadas setas bidirecionais preenchidas para indicar que os estudantes apontaram uma relação de similaridade entre os dois domínios e setas bidirecionais descontínuas para indicar que a similaridade identificada entre os domínios é um atributo de objeto. 


\section{Resultados e discussões}

Durante a discussão das atividades propostas na UD foram observadas diferentes interações argumentativas entre os estudantes do grupo selecionado.

Nesse artigo nos propomos a avaliar o potencial da estratégia de criação e crítica de analogias pelos estudantes para fomentar argumentação no ensino do modelo atômico de Thomson. Para isso, analisamos a interação dialógica que ocorreu durante o ensino desse tema, visando observar como essa interação se caracteriza como argumentativa e como ela contribuiu para o ensino do tema. O quadro 1 apresenta o recorte do diálogo entre os estudantes, a pesquisadora $(\mathrm{P})$ e a professora $(\mathrm{Pr})$ durante um dos momentos de criação e crítica de analogias.

Quadro 1 - Interação argumentativa durante a criação e crítica de comparações sobre o modelo atômico de Thomson

\begin{tabular}{|c|c|c|}
\hline $\begin{array}{l}\text { Turnos } \\
\text { de fala }\end{array}$ & Transcrição & Esclarecimentos \\
\hline 1 & $\begin{array}{l}\text { [Pr]: Então gente. Entenderam? Só que agora, vocês vão } \\
\text { fazer essa comparação para o átomo de Thomson, para esse } \\
\text { modelo que vocếs representaram aí. Para ficar mais fácil da } \\
\text { gente entender, vocês vão pensar em algo familiar a vocês. } \\
\text { O que vocês costumam ver no dia a dia de vocês que vocês } \\
\text { podem pensar assim: "nossa, eu posso comparar isso com o } \\
\text { átomo de Thomson. }\end{array}$ & $\begin{array}{l}\text { A professora problematiza a } \\
\text { situação para os estudantes: } \\
\text { selecionar um análogo para ser } \\
\text { comparado com o modelo atômico } \\
\text { de Thomson. }\end{array}$ \\
\hline 2 & [Caio]: É mesmo, por exemplo, bola de gude... & $\begin{array}{l}\text { Sugere um análogo: bola de gude } \\
\text { (tese 1) }\end{array}$ \\
\hline 3 & $\begin{array}{l}\text { [Carlos]: Que bola de gude o quê! Ela tem energia por } \\
\text { acaso? }\end{array}$ & $\begin{array}{l}\text { Carlos refuta a ideia de Caio e } \\
\text { argumenta a partir da informação de } \\
\text { presença de energia no átomo. }\end{array}$ \\
\hline 6 & [Pr]: Mas gente, tem energia no átomo? & $\begin{array}{l}\text { A professora interrompe a interação } \\
\text { para direcionar o diálogo. }\end{array}$ \\
\hline 7 & [Caio]: Não, elétron. É elétron. & $\begin{array}{l}\text { O estudante avalia sua afirmativa e } \\
\text { diz se referir ao "elétron" quando } \\
\text { disse "energia". }\end{array}$ \\
\hline 8 & $\begin{array}{l}\text { [João]: Eu acho que pode ser a roda do carro porque } \\
\text { quando ela está rodando a esfera tem... [os colegas } \\
\text { interrompem a fala de João com conversas } \\
\text { paralelas] }\end{array}$ & $\begin{array}{l}\text { O estudante começa a sugerir uma } \\
\text { comparação. }\end{array}$ \\
\hline \multicolumn{3}{|c|}{ 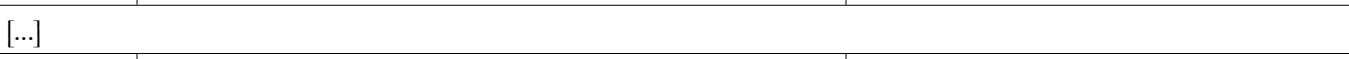 } \\
\hline 13 & $\begin{array}{l}\text { [João]: Tïpo a esfera do carro, quando ela está rodando } \\
\text { tem é... esse negócio elétrico... senão ela não rodava não... }\end{array}$ & $\begin{array}{l}\text { João sugere uma comparação com a } \\
\text { roda de carro como análogo. }\end{array}$ \\
\hline 14 & [Caio]: Mas o carro é elétrico, não é elétron não. & $\begin{array}{l}\text { Caio tenta refutar, afirmando que } \\
\text { o átomo possui elétron e não é elétrico } \\
\text { como o João sugeriu. }\end{array}$ \\
\hline
\end{tabular}


Quadro 1 - continuação

\begin{tabular}{|c|c|c|}
\hline $\begin{array}{l}\text { Turnos } \\
\text { de fala }\end{array}$ & Transcrição & Esclarecimentos \\
\hline 15 & $\begin{array}{l}\text { [P]: Tá. Quando o colega fala assim que pode ser a esfera } \\
\text { do carro... }\end{array}$ & $\begin{array}{l}\text { A pesquisadora começa a auxiliar os } \\
\text { estudantes no mapeamento de suas } \\
\text { comparações. }\end{array}$ \\
\hline 16 & $\begin{array}{l}\text { João]: É no carro tem um tanto de esfera que fica } \\
\text { rodando, de rolamento... }\end{array}$ & $\begin{array}{l}\text { João argumenta em defesa da sua } \\
\text { comparação, esclarecendo que quer } \\
\text { comparar o átomo com o rolamento } \\
\text { (tese 2) presente na roda do carro. }\end{array}$ \\
\hline \multicolumn{3}{|r|}{ 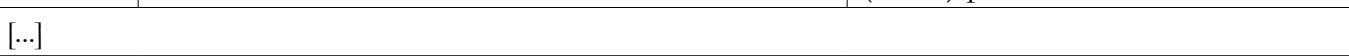 } \\
\hline 19 & $\begin{array}{l}\text { [P]: Aqui, vocês estão pensando assim: 'ab eu tenho que } \\
\text { comparar com algo que tenha energia, eletricidade...' Não } \\
\text { necessariamente gente. Quando o colega fala assim 'eu } \\
\text { quero comparar com a roda, porque ela se movimenta', } \\
\text { pensando naquela movimentação do arco, não é? Não } \\
\text { precisa de ser alguma coisa capaz de se perceber a presença } \\
\text { dos elétrons, vocês podem pensar que é semelhante a alguma } \\
\text { coisa que tenha a movimentação que os elétrons tem... ou } \\
\text { alguma coisa que tenha alguma outra característica que o } \\
\text { átomo tem... Mas não precisa ser alguma coisa que tenha a } \\
\text { carga explicitamente. Entenderam? }\end{array}$ & $\begin{array}{l}\text { A pesquisadora tenta auxiliar os } \\
\text { estudantes na evolução de suas } \\
\text { comparações. }\end{array}$ \\
\hline 20 & [Carlos]: Entendi... & $\begin{array}{l}\text { Carlos afirma compreender a } \\
\text { explicação dada pela professora. }\end{array}$ \\
\hline 21 & [Pr]: Então, pensem aí... & $\begin{array}{l}\text { Nesse momento a pesquisadora e a } \\
\text { professora se ausentam do grupo. }\end{array}$ \\
\hline 22 & [Caio]: Roda de bicicleta... & $\begin{array}{l}\text { Caio sugere um análogo: roda de } \\
\text { bicicleta (tese 3). }\end{array}$ \\
\hline 23 & [João]: Roda de bicicleta é esférico por acaso? & $\begin{array}{l}\text { João argumenta em função da tese } 3 \\
\text { não compartilhar similaridade física } \\
\text { com o átomo. }\end{array}$ \\
\hline 24 & $\begin{array}{l}\text { [Caio]: Tá. Rolimã. Carrinho de rolimã. A rolimã está } \\
\text { rolando tem um tanto de esfera por dentro uai... Ele tem } \\
\text { elétron onde? }\end{array}$ & $\begin{array}{l}\text { Caio retoma o análogo rolamento } \\
\text { (tese 2) e começa uma avaliação da } \\
\text { comparação a partir da procura de } \\
\text { informações sobre o átomo. }\end{array}$ \\
\hline 25 & [Arthur]: Na esfera nai... & $\begin{array}{l}\text { Arthur auxilia Caio na elaboração de } \\
\text { ideias sobre o átomo. }\end{array}$ \\
\hline \multicolumn{3}{|r|}{ 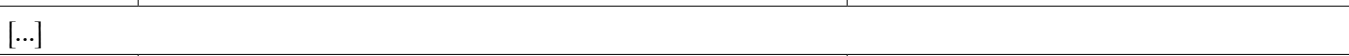 } \\
\hline 32 & [Arthur]: Rolimã... É... Tem esfera e gira, não gira? & $\begin{array}{l}\text { Arthur defende a tese } 2 \text { e argumenta } \\
\text { a partir da informação sobre a } \\
\text { semelhança de movimentação entre } \\
\text { o análogo e o conceito. }\end{array}$ \\
\hline$[\ldots]$ & & \\
\hline
\end{tabular}


Quadro 1 - continuação

\begin{tabular}{|c|c|c|}
\hline $\begin{array}{l}\text { Turnos } \\
\text { de fala }\end{array}$ & Transcrição & Esclarecimentos \\
\hline 36 & {$[\mathrm{P}]:$ Quais foram as ideias ai gente? } & $\begin{array}{l}\text { A pesquisadora retoma ao grupo } \\
\text { e solicita que os estudantes } \\
\text { apresentem suas ideias. }\end{array}$ \\
\hline 37 & $\begin{array}{l}\text { [Caio]: Um falou roda, outro falou rolimã, carrinho de } \\
\text { rolimã... }\end{array}$ & $\begin{array}{l}\text { Caio expõe os análogos que foram } \\
\text { sugeridos. }\end{array}$ \\
\hline \multicolumn{3}{|l|}{$[\ldots]$} \\
\hline 41 & $\begin{array}{l}{[\mathrm{P}]: \text { Tá. E como é a rolimã? Me explica para eu }} \\
\text { entender... }\end{array}$ & $\begin{array}{l}\text { A pesquisadora solicita } \\
\text { esclarecimentos aos estudantes. }\end{array}$ \\
\hline \multicolumn{3}{|c|}{ ( } \\
\hline 48 & $\begin{array}{l}\text { [Arthur]: Tem tipo um monte de esfera dentro... } \\
\text { [o estudante faz um desenho para auxiliar a } \\
\text { pesquisadora no entendimento sobre o rolamento] } \\
\text { Seria assim [mostrando para o desenho] aqui, tem } \\
\text { tipo um eixo central, e esse fica parado enquanto os outros } \\
\text { estão girando }\end{array}$ & $\begin{array}{l}\text { O estudante desenha o rolamento } \\
\text { para auxiliá-lo em sua explicação } \\
\text { para a pesquisadora. }\end{array}$ \\
\hline 49 & [P]: Tá. Beleza. E o que pode ser comparado aí? & $\begin{array}{l}\text { A pesquisadora solicita o } \\
\text { mapeamento da comparação. }\end{array}$ \\
\hline 50 & $\begin{array}{l}\text { [Carlos]: Igual lá, fica girando com elétrons, e tem as } \\
\text { esferas... }\end{array}$ & $\begin{array}{l}\text { Carlos mapeia as correspondências } \\
\text { da comparação. }\end{array}$ \\
\hline 51 & [João]: Mas os elétrons ficam dentro da esfera. & $\begin{array}{l}\text { João argumenta acrescentando uma } \\
\text { nova informação sobre a localização } \\
\text { dos elétrons. }\end{array}$ \\
\hline \multicolumn{3}{|r|}{ 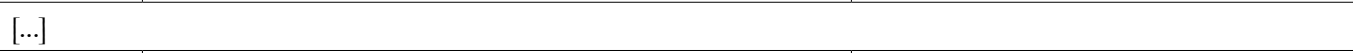 } \\
\hline 55 & $\begin{array}{l}\text { [Carlos]: Tem a roda de bicicleta também, que tem os } \\
\text { raios... A roda gira, tem os raios que pode ser tipo os } \\
\text { elétrons... }\end{array}$ & $\begin{array}{l}\text { Carlos retoma análogo (tese } 3 \text { ) e } \\
\text { argumenta em defesa, a partir da } \\
\text { correspondência da comparação. }\end{array}$ \\
\hline \multicolumn{3}{|c|}{ ( } \\
\hline 57 & $\begin{array}{l}\text { P]: E ai gente, vocês concordam? Porque você está achando } \\
\text { que é bobeira, Caio? }\end{array}$ & $\begin{array}{l}\text { A pesquisadora solicita que } \\
\text { os estudantes justifiquem seus } \\
\text { posicionamentos. }\end{array}$ \\
\hline 58 & $\begin{array}{l}\text { [Arthur]: Ah... Acho que dá uai, tem aqueles raios, e... } \\
\text { está em constante movimento... }\end{array}$ & $\begin{array}{l}\text { Arthur defende a tese } 3 \text { e argumenta } \\
\text { a partir da correspondência do } \\
\text { análogo com a movimentação dos } \\
\text { elétrons no átomo. }\end{array}$ \\
\hline 59 & $\begin{array}{l}\text { [Caio]: Mas a roda é assim [faz gestos se referindo } \\
\text { ao fato da roda não ser uma esfera e, sim um } \\
\text { círculo] }\end{array}$ & $\begin{array}{l}\text { Caio avalia a tese } 3 \text { e destaca a } \\
\text { limitação dela não compartilhar } \\
\text { similaridade física com o átomo. }\end{array}$ \\
\hline \multicolumn{3}{|l|}{$[\ldots]$} \\
\hline 63 & {$[\mathrm{P}]:$ E aí o que seria isso [se referindo aos 'raios']? } & $\begin{array}{l}\text { A pesquisadora solicita o } \\
\text { mapeamento. }\end{array}$ \\
\hline
\end{tabular}


Quadro 1 - continuação

\begin{tabular}{|c|c|c|}
\hline $\begin{array}{l}\text { Turnos } \\
\text { de fala }\end{array}$ & Transcrição & Esclarecimentos \\
\hline 64 & $\begin{array}{l}\text { [Arthur]: Seria os elétrons igual no outro [se referindo } \\
\text { ao modelo deles para representar o átomo de } \\
\text { Thomson]... }\end{array}$ & $\begin{array}{l}\text { O estudante apresenta a } \\
\text { correspondência entre os domínios. }\end{array}$ \\
\hline 65 & $\begin{array}{l}{[\mathrm{P}]: \text { Mas aí [se referindo ao análogo bicicleta], os }} \\
\text { elétrons eles estão em anéis ou estão nessa forma aí, como é } \\
\text { a roda da bicicleta? Isso não é anel, né? }\end{array}$ & $\begin{array}{l}\text { A pesquisadora questiona } \\
\text { os estudantes para que eles } \\
\text { identifiquem a limitação } 0^{5} \text { na analogia } \\
\text { sugerida por eles. }\end{array}$ \\
\hline \multicolumn{3}{|r|}{ 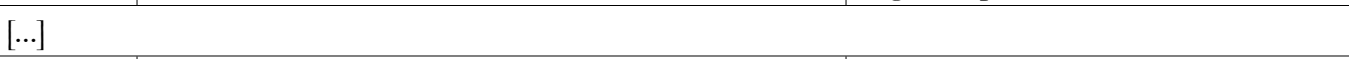 } \\
\hline 67 & $\begin{array}{l}\text { [João]: É tipo assim, que o formato da roda é o formato } \\
\text { da esfera e por dentro são os raios e os raios são os } \\
\text { elétrons... }\end{array}$ & $\begin{array}{l}\text { João justifica seu ponto de vista } \\
\text { a partir do mapeamento da } \\
\text { comparação. }\end{array}$ \\
\hline 68 & [Arthur]: E aí fica girando... & $\begin{array}{l}\text { Arthur complementa o mapeamento } \\
\text { feito por João acrescentando uma } \\
\text { nova informação. }\end{array}$ \\
\hline 69 & $\begin{array}{l}{[\mathrm{P}]: \text { Mas aí, aqui na roda de bicicleta o que gira é o quê? }} \\
\text { Só a roda. Os anéis dos elétrons, eles giram? }\end{array}$ & $\begin{array}{l}\text { A pesquisadora questiona } \\
\text { auxiliando-os no mapeamento da } \\
\text { analogia. }\end{array}$ \\
\hline 70 & [Arthur]: Junto né... & $\begin{array}{l}\text { Arthur afirma que no átomo os } \\
\text { anéis contendo elétrons giram junto } \\
\text { da esfera que representa o átomo. }\end{array}$ \\
\hline 71 & $\begin{array}{l}{[\mathrm{P}]: \text { E no átomo? Esses elétrons que estão em anéis eles }} \\
\text { giram juntos com a esfera ou eles giram diferente, giram lá } \\
\text { dentro? }\end{array}$ & $\begin{array}{l}\text { Pesquisadora questiona com a } \\
\text { intenção de auxiliar os estudantes a } \\
\text { refletirem sobre a movimentação do } \\
\text { elétron dentro do átomo. }\end{array}$ \\
\hline 72 & [João]: Giram diferente... & $\begin{array}{l}\text { João afirma que a movimentação } \\
\text { dos elétrons é independente da } \\
\text { movimentação da esfera do átomo. }\end{array}$ \\
\hline 73 & [Arthur]: Ab! Espera aí... Tem roda de carro também... & $\begin{array}{l}\text { Arthur sugere um nova solução: } \\
\text { roda de carro (tese 4). }\end{array}$ \\
\hline 74 & [Carlos]: $A b e ́ !$ & Carlos concorda com a tese 4 \\
\hline 75 & $\begin{array}{l}\text { [Arthur]: Que a roda é assim, o carro freia, mas por } \\
\text { dentro continua rodando ainda... }\end{array}$ & $\begin{array}{l}\text { Arthur utiliza explicação para } \\
\text { esclarecer sobre o análogo. }\end{array}$ \\
\hline \multicolumn{3}{|c|}{ e } \\
\hline 78 & $\begin{array}{l}\text { [joão]: É. O carro pára e a roda continua girando... Só } \\
\text { por dentro da roda. }\end{array}$ & $\begin{array}{l}\text { João argumenta em defesa da tese } 4 \\
\text { ressaltando a similaridade entre os } \\
\text { dois domínios. }\end{array}$ \\
\hline
\end{tabular}

\footnotetext{
${ }^{5}$ Aspectos não comparáveis entre o domínio análogo e o alvo.
} 
Quadro 1 - continuação

\begin{tabular}{|l|l|l|}
\hline $\begin{array}{l}\text { Turnos } \\
\text { de fala }\end{array}$ & \multicolumn{1}{|c|}{ Transcrição } & \multicolumn{1}{|c|}{ Esclarecimentos } \\
\hline 79 & $\begin{array}{l}\text { [P]: Entendi. E aí seria o quê? Essa roda girando lá } \\
\text { dentro? }\end{array}$ & $\begin{array}{l}\text { A pesquisadora solicita detalhes do } \\
\text { mapeamento. }\end{array}$ \\
\hline 80 & $\begin{array}{l}\text { [joão]: Os elétrons... Que daí eles não rodam junto com a } \\
\text { esfera... }\end{array}$ & $\begin{array}{l}\text { João expressa a relação de } \\
\text { similaridade. }\end{array}$ \\
\hline 81 & $\begin{array}{l}{[\text { Arthur]: A esfera está tipo parada e os elétrons girando }} \\
\text { por dentro... }\end{array}$ & $\begin{array}{l}\text { Arthur defende a comparação: } \\
\text { movimentação dos elétrons } \\
\text { independente da movimentação da } \\
\text { esfera do átomo. }\end{array}$ \\
\hline
\end{tabular}

Fonte: elaborado pelas autoras.

No quadro 1 observamos que, como destacado por Ferraz e Sasseron (2017), as interações da pesquisadora com propósitos de problematizar a situação (turno 1), explorar pontos de vistas (turnos 57, 41) e qualificar as informações (turno 65) contribuíram para que os estudantes se envolvessem em argumentação. A partir daqueles propósitos, os estudantes se envolveram em interações para solucionar o problema (turnos 2, 22), defender ideias (turno 58) e justificar pontos de vista (turnos 67 e 68).

Observamos que o fato dos estudantes estarem em um contexto de criação de analogias, possibilitou que eles apresentassem os argumentos e pontos de vista a partir de um domínio que lhes era familiar (análogo), o que facilitou a expressão de ideias por eles, mesmo em momentos de discussão sem a presença da pesquisadora ou da professora (por exemplo, turnos 24 e 32$)$.

O contexto de criação e crítica de analogias pelos estudantes também oportunizou momentos de avaliação de suas ideias (por exemplo, turnos 22, 23, 24), acarretando em 'eliminação' dos análogos ou fortalecimento e fundamentação das comparações criadas. Christodoulou e Osborne (2014) ressaltam a importância da promoção desse processo de avaliação pelos professores, uma vez que estes se preocupam demasiadamente com as justificativas e nem sempre se atentam para as críticas sobre as ideias dos estudantes.

As teses discutidas durante essa interação são apresentadas nos quadros 2, 3, 4 e 5. Observamos que a interação argumentativa foi finalizada quando o problema sobre a escolha do análogo mais adequado foi resolvido. Isso ocorreu quando houve o abandono dos análogos iniciais (birosca, roda de bicicleta e rolamento) e a proposição de um novo análogo (roda de carro) em que os estudantes visualizaram maior potencial para representar as ideias sobre o modelo.

Quadro 2 - Representação da correspondência da tese 1

\begin{tabular}{|c|c|c|}
\hline Bola de gude (análogo) & Correspondências & Modelo atômico de Thomson (alvo) \\
\hline Esférica & $\sqrt{ }|||||||||||||||||||||||||||||||||| \mid)$ & Esférico \\
\hline
\end{tabular}

Fonte: elaborado pelas autoras. 
Argumentação de estudantes na criação e crítica ...

Quadro 3 - Representação da correspondência e limitação da tese 2

\begin{tabular}{|c|c|c|}
\hline Roda de bicicleta (análogo) & Correspondências & Modelo atômico de Thomson (alvo) \\
\hline Aro girando na roda & & $\begin{array}{c}\text { Elétrons girando em anéis dentro do } \\
\text { átomo }\end{array}$ \\
\hline
\end{tabular}

Fonte: elaborado pelas autoras.

Quadro 4 - Representação da correspondência da tese 3

\begin{tabular}{|c|c|c|}
\hline Rolamento (análogo) & Correspondências & Modelo atômico de Thomson (alvo) \\
\hline $\begin{array}{c}\text { Movimentação das esferas no } \\
\text { sistema de rolamento }\end{array}$ & & $\begin{array}{c}\text { Movimentação dos elétrons } \\
\text { no átomo }\end{array}$ \\
\hline
\end{tabular}

Fonte: elaborado pelas autoras.

Quadro 5 - Representação das correspondências da tese 4

\begin{tabular}{|l|l|l|}
\hline \multicolumn{1}{|c|}{$\begin{array}{c}\text { Roda de carro } \\
\text { (análogo) }\end{array}$} & Correspondências & \multicolumn{1}{|c|}{$\begin{array}{c}\text { Modelo atômico de } \\
\text { Thomson (alvo) }\end{array}$} \\
\hline $\begin{array}{l}\text { Anel girando dentro da circunferência } \\
\text { da roda }\end{array}$ & & $\begin{array}{l}\text { Elétrons girando em anéis dentro } \\
\text { da esfera do átomo }\end{array}$ \\
\hline $\begin{array}{l}\text { Anel girando no interior da roda } \\
\text { independente da movimentação da roda }\end{array}$ & $\begin{array}{l}\text { Anel girando independente da } \\
\text { movimentação da esfera }\end{array}$ \\
\hline
\end{tabular}

Fonte: elaborado pelas autoras.

A partir dos quadros 2, 3, 4 e 5 observamos que os estudantes sugeriram três comparações do tipo analogia (quadros 3, 4 e 5) e uma comparação do tipo mera aparência (quadro 1). Notamos que a evolução do tipo de comparação permitiu um avanço das ideias dos estudantes sobre o conhecimento científico. Isso pode ser notado, por exemplo, quando eles criaram a analogia entre a roda de bicicleta e o modelo atômico de Thomson. Naquele momento, eles conseguiram inferir o raciocínio da movimentação dos elétrons dentro do átomo a partir da movimentação da roda de bicicleta (turnos 67 e 68) sem a necessidade de correspondências físicas entre os mesmos. Percebemos também que os estudantes conseguiram visualizar novos aspectos sobre o conceito alvo (como por exemplo, movimentação dos anéis de elétrons) quando começaram a estabelecer relações de caráter mais abstrato.

\footnotetext{
${ }^{6}$ Apesar de considerarmos válidas as relações estabelecidas pelos estudantes na analogia entre a roda de carro e o átomo de Thomson, sabemos que elas não são coerentes com o funcionamento da roda do carro, uma vez que todo o sistema para (exceto o motor) quando o freio é acionado.
} 
Nesse sentido, é possível notar que, quando os estudantes conseguiram evoluir no estabelecimento de relações de similaridade, o processo argumentativo progrediu com argumentos que exploravam informações mais relevantes para a compreensão do modelo (turno 51) do que quando eles vislumbravam comparações de mera aparência (turno 23). Observamos que quando os estudantes propunham este tipo de comparação entre os domínios, isso dificultava a fundamentação dos argumentos, porque eles não realizavam um raciocínio inferencial, mas se restringiam às correspondências de similaridades superficiais. Em outras palavras, os estudantes buscavam por análogos equivalentes ao alvo e não similares a este. Ao contrário, a literatura afirma que o potencial das analogias está, justamente, no fato delas possibilitarem a exploração de semelhanças relacionais que podem permitir inferências de um domínio para o outro (AUBUSSON; HARRISON; RITCHIE, 2006).

No decorrer das interações discursivas, observamos que os estudantes conseguiram avançar no entendimento sobre o tema a partir da negociação de representações, pois, inicialmente, eles representaram o átomo como uma esfera (comparação com a birosca), mas, posteriormente apresentaram comparações que buscavam representar a movimentação dos elétrons (a partir da comparação com o rolamento, com a roda de bicicleta e com a roda de carro). Assim, mesmo na ausência de palavras adequadas (linguagem científica) para caracterizar o modelo atômico, através das conexões que os estudantes conseguiram estabelecer entre as representações criadas e o modelo científico, eles demonstram sinais de avanço em seus entendimentos (PADILHA; CARVALHO, 2011).

Aliado a isso, como destacado por Osborne (2016), é nas interações com os pares que os estudantes acessam diferentes saberes, evidências e têm suas habilidades lógicas e metacognitivas estimuladas; elementos importantes para o estabelecimento de práticas que se aproximam do fazer científico.

Destacamos que, além de resultados referentes à criação de um ambiente argumentativo a partir das analogias, esse trabalho traz contribuições a respeito do potencial da criação de analogias pelos próprios estudantes como uma estratégia favorável à compreensão do tema modelo atômico de Thomson. Essa estratégia pode sanar problemas referentes à falta de familiaridade dos estudantes com o análogo, pois são eles próprios que criam as comparações. Além disso, a estratégia pode favorecer a fundamentação de ideias mais coerentes sobre o átomo, pois como observamos a partir da interação vista no quadro 1, os estudantes desenvolveram comparações que visavam representar um átomo que possui elétrons em constante movimento, aspecto que não pode ser compreendido a partir da analogia com o pudim de ameixa (RAMOS; MOZZER, 2018).

Nesse sentido, o que observamos é que, durante o processo de criação e crítica de comparações sobre o modelo atômico de Thomson, os estudantes desenvolveram ideias coerentes relacionadas à visualização de um átomo dinâmico (turno 81), no qual os elétrons encontram-se em constante movimento (turnos 67 e 68) e se envolveram em argumentação ao identificarem as: (i) limitações das comparações com o objetivo de refutá-las (por exemplo, turnos 23 e 51); e, (ii) correspondências de similaridades com a intenção de defendê-las (por exemplo, turnos 55 e 58). 


\section{Conclusões e implicações}

A análise conduzida neste trabalho evidencia que, como os estudantes tinham o objetivo de selecionar comparações coerentes com as ideias do modelo atômico de Thomson, eles se envolveram em argumentação ao apresentarem as correspondências das relações de similaridade e as limitações das comparações que eles criavam. As correspondências eram salientadas para demonstrar o potencial daquelas comparações em expressar as ideias sobre o modelo atômico e defender as mesmas, enquanto as limitações, na maioria das vezes, eram ressaltadas com o objetivo de refutar ou invalidar as comparações propostas.

O processo de explicitação das correspondências de similaridade compartilhadas entre análogo e o alvo, ou seja, o mapeamento da comparação, também é essencial qualquer que seja o modo de utilização das analogias no ensino, pois, sem essa explicitação, a comparação torna-se apenas uma linguagem metafórica, que pode levar a generalizações e raciocínios equivocados (HAGLUND; JEPPSSON, 2012). Nossa análise evidencia que o processo argumentativo favoreceu a expressão do mapeamento das comparações na medida em que os estudantes não conseguiam defender e realçar o potencial explicativo de suas representações sem a explicitação das correspondências.

A expressão das limitações das comparações também é algo essencial durante a apresentação delas no contexto de ensino, pois nunca existirá uma equivalência perfeita entre o análogo e o alvo (DUIT, 1991). Em nosso contexto, a argumentação favoreceu a expressão das limitações das comparações pelos estudantes e, quando elas contradiziam completamente as ideias do modelo atômico de Thomson, eles abandavam aquela comparação e propunham uma nova.

Além disso, o processo de exploração das limitações favoreceu interações avaliativas, nas quais as ideias dos estudantes sobre o tema eram julgadas e examinadas a partir de uma análise sobre as comparações expressas por eles. As interações avaliativas durante a argumentação são fundamentais, mas nem sempre elas são exploradas no ensino (CHRISTODOTOULOU; OSBORNE, 2014). O contexto de criação e crítica de analogias favoreceu essa exploração na medida em que era necessário legitimar aquelas comparações e para isso era importante destacar as limitações delas e avaliar a pertinência das relações de similaridade estabelecidas nas mesmas.

Observamos que a argumentação ocasionada na discussão das correspondências e limitações das comparações dos estudantes também influenciou a atribuição de significados sobre o modelo atômico, pois permitiu que eles fundamentassem as escolhas das comparações a partir de informações apresentadas nos argumentos. Isso fez com que eles buscassem elaborar novas comparações, mais abrangentes e coerentes com as ideias do modelo atômico de Thomson, quando não visualizavam potencial nas relações de similaridade para representar tais ideias.

Esse resultado evidencia que o envolvimento dos estudantes em argumentação permitiu que eles discutissem e (re)elaborassem ideias sobre o conhecimento científico que poderiam não ter sido abordadas se eles, por exemplo, somente criassem representações sem discuti-las. Ademais, o fato dos estudantes se envolverem em argumentação sobre suas representações, possibilitou que a professora e a pesquisadora reconhecessem as ideias deles e atuassem de modo a auxiliá-los na (re)elaboração dos conhecimentos. 
Desse modo, nosso trabalho fornece evidências adicionais de que a estratégia de criação e crítica de analogias pode contribuir para a aprendizagem e para a participação dos estudantes no discurso de sala de aula. Aliado a isso, consideramos que essa pode ser uma estratégia utilizada no contexto do ensino do modelo atômico de Thomson, uma vez que diferentes problemas decorrentes do uso de representações e analogias prontas, como a falta de familiaridade dos estudantes com o análogo, têm sido destacados na literatura (LOPES; MARTINS, 2009; RAMOS; MOZZER, 2018).

O uso dessa estratégia pode evitar problemas como o mencionado, visto que os próprios estudantes são criadores de suas comparações. Além disso, considerando-se a problemática da analogia entre o pudim de ameixa e o modelo atômico de Thompson para a compreensão da dinamicidade dos elétrons no átomo (RAMOS; MOZZER, 2018) essa estratégia se demonstrou eficiente para que os estudantes se atentassem para a característica dinâmica do modelo e, inclusive, desenvolvessem comparações mais coerentes para representar essa ideia.

Considerando-se que pesquisas em diferentes contextos devem ser desenvolvidas para se avaliar o potencial de uma estratégia, sugerimos que investigações adicionais sejam realizadas no sentido de avaliar as possíveis contribuições dessa estratégia para o aprendizado de outros temas químicos e em outros domínios das ciências.

\section{Agradecimentos}

As autoras agradecem ao Conselho Nacional de Desenvolvimento Científico e Tecnológico (CNPq), à Coordenação de Aperfeiçoamento de Pessoal de Nível Superior (CAPES), Código de Financiamento 001, e à Fundação de Amparo à Pesquisa do Estado de Minas Gerais (FAPEMIG) pelo apoio financeiro para a realização da pesquisa.

\section{Referências}

ANDRADE, G. M.; MOZZER, N. B. Análise dos questionamentos do professor em atividades fundamentadas em modelagem analógica. Revista Brasileira de Pesquisa em Educação em Ciências, Belo Horizonte, v. 16, n. 3, p. 825-850, 2016.

AUBUSSON, P.; HARRISON, A. G.; RITCHIE, S. M. Metaphor and analogy: Serious thought in science education. In: AUBUSSON, P. J.; HARRISON, A. G.; RITCHIE, S. M. (ed.). Metaphor and analogy in science education. Dordrecht: Springer, 2006. p. 1-9.

BAKER, M. Argumentative interactions and the social construction of knowledge. In: MIRZA, N. M.; PERRET-CLERMONT, A.-N. (ed.). Argumentation and education: theoretical foundations and practices. Dordrecht: Springer, 2009. p. 127-144.

CHRISTODOULOU, A.; OSBORNE, J. The science classroomas a site of epistemic talk: a case study of a teacher's attempts to teach science based on argument. Journal of Research in Science Teaching, Hoboken, v. 51, n. 10, p. 1275-1300, 2014.

COLL, R. K. The role of models/and analogies in science education: implications from research. International Journal of Science Education, Abingdon, v. 27, n. 2, p. 183-198, 2005. 
COHEN, L.; MANION, L.; MORRISON, K. Research methods in education. 7. ed. Abingdon: Routledge, 2011.

DUIT, R. On the role of analogies and metaphors in learning science. Science Education, Hoboken, v. 75, n. 6, p. 649-672, 1991.

DUNBAR, K.; BLANCHETTE, I. The in vivo / in vitro approach to cognition: the case of analogy. Trends in Cognitive Sciences, Kidlington, v. 5, n. 8, p. 334-339, 2001.

EMIG, B. R.; McDONALD, S.; ZEMBAL-SAUL, C.; STRAUSS, S. G. Inviting argument by analogy: analogical-mapping-based comparison activities as a scaffold for small-group argumentation. Science Education, Hoboken, v. 98, n. 2, p. 243-268, 2014. DOI: https:// doi.org/10.1002/sce.21096.

FERRAZ, A. T.; SASSERON, L. H. Propósitos epistêmicos para a promoção da argumentação em aulas investigativas. Investigações em Ensino de Ciências, Porto Alegre, v. 22, n. 1, p. 42-60, 2017.

GENTNER, D. The mechanisms of analogical learning. In: VOSNIADOU, S.; ORTONY, A. (ed.). Similarity and analogical reasoning. Cambridge: Cambridge University Press, 1989. p. 199-241.

GILBERT, J.; BOULTER, C.; ELMER, R. Positioning models in science education and in design and technology education. In: GILBERT, J.; BOULTER, C. (ed.). Developing models in science education. Dordrecht: Kluwer, 2000. p. 3-17.

HAGLUND, J.; JEPPSSON, F. Using self-generated analogies in teaching of thermodynamics. Journal of Research in Science Teaching, Hoboken, v. 49, n. 7, p. 898-921, 2012.

JIMÉNEZ-ALEIXANDRE, M. P.; CRUJEIRAS, B. Epistemic practices and scientific practices in science education. In: TABER, K. S.; AKPAN, B. (ed.). Science education: an international course companion. Rotterdam: Sense Publishers, 2017. p. 69-80. DOI: https:// doi.org/10.1007/978-94-6300-749-8_5.

JUSTI, R.; MENDONÇA, P. C. C. Usando analogias com função criativa: uma nova estratégia para o ensino de química. Educación Química, Barcelona, v. 1, n. 1, p. 24-29, 2008. DOI: https://doi.org/10.2436/20.2003.02.4.

KELLY, G. J.; REGEV, J.; PROTHERO, W. Analysis of line of reasoning in written argumentation. In: ERDURAN, S.; JIMÉNEZ-ALEIXANDRE, M. P. (ed.). Argumentation in science education: perpectives from classroom-based research. Dordrecht: Springer, 2008. p. 137-158.

LONGINO, H. E. The fate of knowledge. Princeton: Princeton University Press, 2002.

LOPES, C. V. M.; MARTINS, R. A. Thomson e o uso de analogias para explicar os modelos atômicos: o 'pudim de passas' nos livros texto. In: ENCONTRO NACIONAL DE PESQUISA EM EDUCAÇÃO EM CIÊNCIAS, 7., 2009, Florianópolis. Anais [...]. Belo Horizonte: ABRAPEC, 2009. Disponível em: http://posgrad.fae.ufmg.br/posgrad/ viienpec/pdfs/1682.pdf. Acesso em: 6 ago. 2019. 
MOZZER, N. B.; JUSTI, R. "Nem tudo que reluz é ouro": uma discussão sobre analogias e outras similaridades e recursos utilizados no ensino de ciências. Revista Brasileira de Pesquisa em Educação em Ciências, Belo Horizonte, v. 15, n. 1, p. 123-147, 2015.

NERSESSIAN, N. J. How do scientists think?: capturing the dynamics of conceptual change in science. In: GIERE, R. N. (ed.). Cognitive models of science. Minneapolis: University of Minnesota Press, 1992. p. 3-44.

OSBORNE, J. Defining a knowledge base for reasoning in science: the role of procedural and epistemic knowledge. In: DUSHL, R. A.; BISMARCK, A. S. (ed.). Reconceptualizing STEM education: the central role of practice. New York: Routledge, 2016. p. 215-231.

PADILHA, J. N.; CARVALHO, A. M. P. Relações entre os gestos e as palavras utilizadas durante a argumentação dos alunos em uma aula de conhecimento físico. Revista Brasileira de Pesquisa em Educação em Ciências, Belo Horizonte, v. 11, n. 2, p. 25-40, p. 2011.

RAMOS, T. C. Influência da criação e crítica de analogias por estudantes de química do ensino médio na promoção de ambientes argumentativos. 2017. Dissertação (Mestrado em Educação) - Universidade Federal de Ouro Preto, Ouro Preto, 2017.

RAMOS, T. C.; MOZZER, N. B. Análise do uso da analogia com o "pudim de passas" guiado pelo TWA no ensino do modelo atômico de Thomson: considerações e recomendações. Química Nova na Escola, São Paulo, v. 40, n. 2, p. 106-115, 2018. DOI: https://doi.org/10.21577/0104-8899.20160111.

RAMOS, T. C.; MENDONÇA, P. C.; MOZZER, N. B. Argumentação na elaboração e crítica de analogias: unidade didática para o ensino dos modelos atômicos. In: ENCONTRO NACIONAL DE ENSINO DE QUÍMICA, 18., 2016, Florianópolis. Anais [...].

Florianópolis: UFSC, 2016.

SANTOS, W. L. P.; MOL, G. S. (coord.). Química cidadã volume 1: ensino médio. 3. ed. São Paulo: AJS, 2016.

SASSERON, L. H.; DUSCHL, R. A. Ensino de ciências e as práticas epistêmicas: o papel do professor e o engajamento dos estudantes. Investigações em Ensino de Ciências, Porto Alegre, v. 21, n. 2, p. 52-67, 2016.

STAKE, R. Case studies. In: DENZIN, N. K.; LINCOLN, Y. S. (ed.). The handbook of qualitative research. Thousand Oaks: Sage, 2000. p. 435-454.

Submetido em 04/12/2017. Aceito em 28/02/2019

Contato: Universidade Federal de Ouro Preto, Campus Morro do Cruzeiro, Ouro Preto, MG, 35400-000, Brasil. 